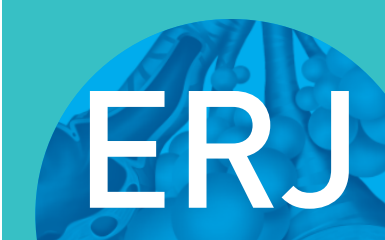

open research
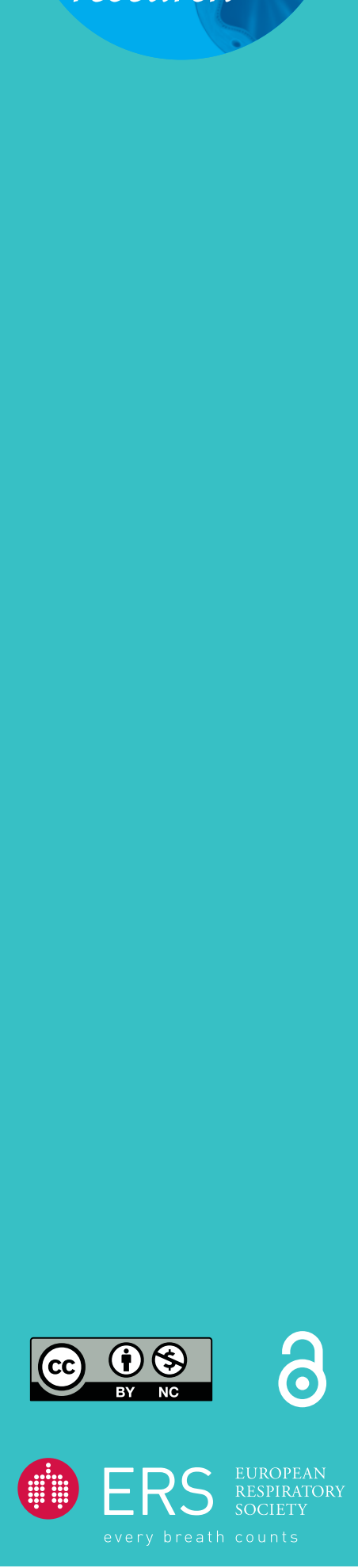

\section{Effect of cladribine therapy on lung cysts in pulmonary Langerhans cell histiocytosis}

\author{
To the Editor:
}

Langerhans cell histiocytosis (LCH) is a group of disorders with variable presentations and outcomes. Children with LCH primarily have bone and multisystem involvement with little impact of lung involvement and usually no treatment indication for lung disease [1, 2]. Conversely, pulmonary involvement is the main determinant of morbidity and mortality in adults and is usually resistant to first-line chemotherapeutic agents used in children [3]. Pulmonary LCH belongs to the spectrum of LCH and is primarily found in smoker adults. In most cases, quitting smoking results in clinical, functional and radiological improvement at early or nodulo-cystic stages [4]. In those with progressive disease and significant lung function impairment, cladribine (a purine nucleoside analog) has been proposed as rescue therapy for progressive, refractory nodulo-cystic disease $[5,6]$. However, there are currently no treatment options for patients with advanced, cystic pulmonary LCH.

Here, we report a case of multisystem LCH with advanced cystic pulmonary LCH in an adult with spectacular response to cladribine. Briefly, a 34-year-old female, current smoker, presenting with polyuria, polydipsia and low-grade fever was diagnosed with central diabetes insipidus and was started on desmopressin replacement therapy. Physical examination was unremarkable with no clinical signs of pulmonary hypertension. Echocardiography was normal. Hypophyseal micro-adenoma was found by brain magnetic resonance imaging. A full endocrinological workup was otherwise normal. Computed tomography (CT) of the chest revealed diffuse bilateral thick-walled cystic lesions and nodules sparing the lung bases (figure 1a and b). Positron emission tomography (PET) with 2-deoxy-2-[fluorine-18] fluoroD-glucose integrated with CT $\left({ }^{18}\right.$ F-FDG PET/CT) showed increased uptake of the lung lesions (figure 1c and d). Since no lung biopsy had been undertaken, a presumptive diagnosis of pulmonary LCH was established. Forced vital capacity (FVC) and forced expiratory volume in $1 \mathrm{~s}$ (FEV1) were $2.85 \mathrm{~L}(74 \%)$ and $2.82 \mathrm{~L}(84 \%)$, respectively. The diffusing capacity of the lung for carbon monoxide (DLCO) was $60 \%$ predicted. The patient quit smoking. However, 6 months later, lung function tests had worsened with decreases of FVC to $2.5 \mathrm{~L}(66 \%)$, FEV1 to $2.2 \mathrm{~L}(67 \%)$ and of DLCO to $57 \%$. After written informed consent, the patient was treated with subcutaneous cladribine $\left(0.1 \mathrm{mg} \cdot \mathrm{kg}^{-1} \cdot \mathrm{day}^{-1}\right.$ for 5 days per course), one course monthly for four consecutive months, along with prophylaxis against herpes zoster virus and Pneumocystis jiroveci, and anti-conceptive hormonal therapy which was continued until 6 months after the discontinuation of cladribine. Treatment was well tolerated. Evaluation after 4 months of treatment demonstrated dramatic improvement in pulmonary function tests, with an increase of FVC to $3.66 \mathrm{~L}$ (96\%), FEV1 to $2.81 \mathrm{~L}(85 \%)$ and of DLCO to $64 \%$. On chest CT, many lung cysts had disappeared and the wall thickness of others had dramatically decreased, while other cysts had paradoxically increased in size (figure 1e and f). No residual abnormal uptake was found on repeated ${ }^{18} \mathrm{~F}$-FDG PET/CT. Yet, the absence of increased uptake of ${ }^{18} \mathrm{~F}-\mathrm{FDG}$ by the lung cysts does not preclude lung function improvement following cladribine therapy [7]. At 1 year, DLCO was $72 \%$ predicted, and volumes were unchanged.

Previously, two reports have been published and suggested the potential efficacy of cladribine in pulmonary LCH at bullo-cystic stage. EpAud et al. [8] described a child who had been treated with

@ERSpublications

Cladribine therapy may be beneficial in advanced forms of pulmonary Langerhans cell histiocytosis, even that with multiple cystic changes http://ow.ly/yeLr30i0Tt6

Cite this article as: Nasser M, Traclet J, Cottin V. Effect of cladribine therapy on lung cysts in pulmonary Langerhans cell histiocytosis. ERJ Open Res 2018; 4: 00089-2017 [https://doi.org/10.1183/ 23120541.00089-2017].

Copyright $\odot$ ERS 2018. This article is open access and distributed under the terms of the Creative Commons Attribution NonCommercial Licence 4.0. 


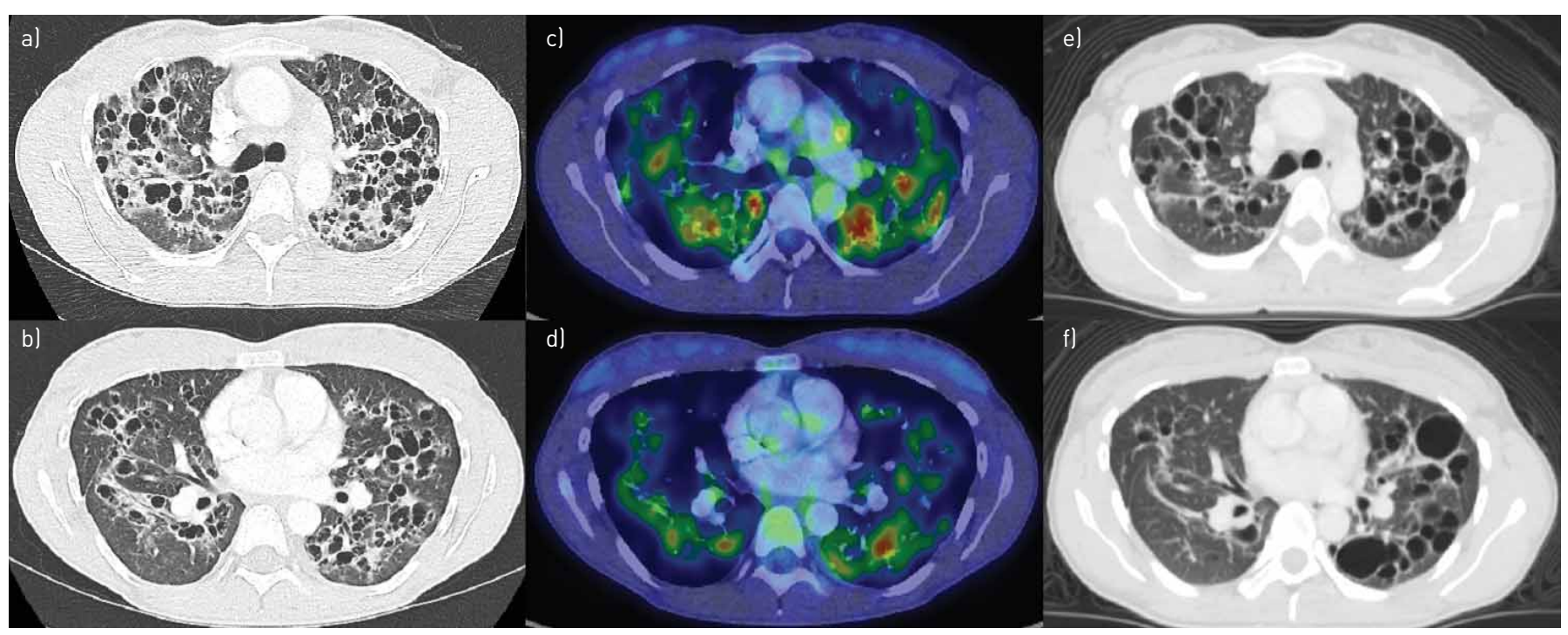

FIGURE 1 a, b, e, f) Computed tomography (CT) of the chest and c, d) positron emission tomography (PET) with 2-deoxy-2-[fluorine-18] fluoro-Dglucose $\left({ }^{18} \mathrm{~F}-\mathrm{FDG}\right)$ integrated with CT at the same anatomic level before (a-d) and after (e, f) cladribine therapy. a, b) Multiple thick-walled cysts of variable size associated with parenchymal infiltrates suggesting infiltration by inflammatory cells are visible. c, d) Increased ${ }^{18} \mathrm{~F}-\mathrm{FDG}$ uptake by lung parenchyma is visible. e, f) Heterogeneous radiological response following cladribine therapy, with disappearance of some cysts, enlargement of others, along with decreased cyst wall thickness and resolution of parenchymal infiltrates is visible.

multiple chemotherapeutic regimens for LCH. Due to lack of efficacy and disease progression, it was decided to introduce cladribine as salvage therapy. In total, the child received six cycles of subcutaneous injection of $5 \mathrm{mg} \cdot \mathrm{m}^{-2}$ of cladribine for 5 days every 4 weeks and had undoubtedly clinical, functional and radiological improvement following cladribine therapy [8]. The most unexpected finding was the decreased number and size of the thick-walled cysts. In another study, LoRILLon et al. [9] reported on the dramatic changes of cysts using cladribine in three current adult smokers with pulmonary LCH, previously treated with corticosteroids with or without vinblastine; yet, one patient had been diagnosed in childhood. Our case is unique because cladribine was the first-line therapy; as a result, chemotherapy preconditioning cannot be counted as a confounding factor as in previous cases. This case highlights the heterogeneous response of lung cysts to cladribine, with some cysts vanishing with treatment while others became enlarged. In addition, the decrease of wall thickness of some cysts, as well as the disappearance of other cysts, correlates well with the finding of KIM et al. [10] who demonstrated that lung cysts in pulmonary $\mathrm{LCH}$ harboured active inflammatory Langerhans cells sheets and florid granulomas regardless of the wall thickness or cyst shape (bizarre or rounded).

Our observation strengthens the evidence of the efficacy of cladribine in advanced stage pulmonary LCH in adults and, therefore, cystic changes should no longer be considered as end stage or irreversible in pulmonary LCH patients. Nevertheless, treatment trials are eagerly awaited to clarify the benefit:risk ratio, and to avoid unnecessary treatment with potentially toxic drugs.

Mouhamad Nasser $\odot^{1}$, Julie Traclet $^{1}$ and Vincent Cottin $\oplus^{1,2}$

${ }^{1}$ Hospices Civils de Lyon, Dept of Respiratory Medicine, National Reference Center for Rare Pulmonary Diseases, Lyon, France. ${ }^{2}$ Claude Bernard Lyon 1 University, University of Lyon, INRA, UMR754, Lyon, France.

Correspondence: Vincent Cottin, Service de pneumologie, hôpital Louis Pradel, 28 avenue Doyen Lepine, F-69677 Lyon Cedex, France. E-mail: vincent.cottin@chu-lyon.fr

Received: July 242017 | Accepted after revision: Dec 212017

Conflict of interest: M. Nasser reports personal fees for travel to meetings from Boehinger Ingelheim, outside the submitted work. J. Traclet reports personal fees for travel to meetings from Boehinger Ingelheim, Roche and Actelion, outside the submitted work. V. Cottin reports personal fees for consultancy, travel to meetings and lectures from Actelion, Novartis and Roche. He reports personal fees for developing educational programmes, consultancy, travel to meetings and lectures from Boehringer Ingelheim. He reports personal fees for consultancy from Bayer, Biogen Idec and MSD, and personal fees 
from Gilead for committee membership. V. Cottin reports personal fees for consultancy and travel to meetings from GSK, and personal fees for consultancy and lectures from Sanofi. He has received grants from Boehringer Ingelheim, GSK, Actelion and Roche, and has received personal fees from Promedior, outside the submitted work.

\section{References}

1 Rigaud C, Barkaoui MA, Thomas C, et al. Langerhans cell histiocytosis: therapeutic strategy and outcome in a 30-year nationwide cohort of 1478 patients under 18 years of age. Br J Haematol 2016; 174: 887-898.

2 Aricò M. Langerhans cell histiocytosis in children: from the bench to bedside for an updated therapy. $\mathrm{Br} J$ Haematol 2016; 173: 663-670.

3 Tazi A, Lorillon G, Haroche J, et al. Vinblastine chemotherapy in adult patients with langerhans cell histiocytosis: a multicenter retrospective study. Orphanet J Rare Dis 2017; 12: 95.

4 Tazi, A, De Margerie C, Naccache JM, et al. The natural history of adult pulmonary Langerhans cell histiocytosis: a prospective multicentre study. Orphanet J Rare Dis 2015; 10: 30.

5 Grobost V, Khouatra C, Lazor R, et al. Effectiveness of cladribine therapy in patients with pulmonary Langerhans cell histiocytosis. Orphanet J Rare Dis 2014; 9: 191.

6 Saven A, Burian C. Cladribine activity in adult langerhans-cell histiocytosis. Blood 1999; 93: 4125-4130.

7 Obert J, Vercellino L, Van Der Gucht A, et al. 18F-fluorodeoxyglucose positron emission tomography-computed tomography in the management of adult multisystem Langerhans cell histiocytosis. Eur J Nucl Med Mol Imaging 2017; 44: 598-610.

8 Epaud R, Ducou Le Pointe H, Fasola S, et al. Cladribine improves lung cysts and pulmonary function in a child with histiocytosis. Eur Respir J 2015; 45: 831-833.

9 Lorillon G, Bergeron A, Detourmignies L, et al. Cladribine is effective against cystic pulmonary Langerhans cell histiocytosis. Am J Respir Crit Care Med 2012; 186: 930-932.

10 Kim, HJ, Lee KS, Johkoh T, et al. Pulmonary langerhans cell histiocytosis in adults: high-resolution CT pathology comparisons and evolutional changes at CT. Eur Radiol 2011; 21: 1406-1415. 